\title{
COMPARISON OF ANALGESIC AND ANTI-INFLAMMATORY ACTIVITIES OF PURIFIED ANTHOCYANIN FROM OSBECKIA ASPERA (L.) BLUME AND OSBECKIA RETICULATA BEDD. USING ANIMAL MODELS
}

\author{
BOSCO LAWARENCE, MURUGAN K* \\ Department of Botany and Biotechnology, Government Arts College, Trivandrum - 695 014, Kerala, India. Email: harimurukan@gmail.com \\ Received: 19 May 2018, Revised and Accepted: 01 September 2018
}

\section{ABSTRACT}

Objective: The objective of the present work is to isolate, purify, and fractionate anthocyanin from selected Osbeckia species and also to compare the analgesic and anti-inflammatory potentiality using animal models.

Methods: Methodologies include extraction of anthocyanin from the in vitro callus culture of Osbeckia aspera and Osbeckia reticulata, purification using amberlite column chromatography, and fractionation by liquid chromatography-tandem mass spectrometry. The analgesic activity was determined by tail immersion method, analgesy meter, hot plate, and acetic acid-induced writhing test. Anti-inflammatory activity was evaluated by carrageenan-induced paw inflammation in mice.

Results: Anthocyanin-producing callus cultures were established in MS medium fortified with various combinations of phytohormones and sucrose. Optimal callus formation in 0 . aspera was initiated on cultures containing $0.5 \mathrm{mg} / \mathrm{L}$ of 2,4 -D, and $0.5 \mathrm{mg} / \mathrm{L} 6$-benzylaminopurine (BA). In 0 . reticulata callus was initiated in the presence of $1.2 \mathrm{mg} / \mathrm{L} \mathrm{BA}$ and $1.4 \mathrm{mg} / \mathrm{L}$ naphthalene acetic acid. The same hormonal combination on extended treatments turned the white friable callus into red compact callus. Anthocyanins obtained from Osbeckia species were purified and fractionated containing malvidin-3-diglucoside, delphinidin, cyanidin aglycone, and peonidin. Purified anthocyanin of $O$. aspera at the concentrations 50, 100, 150, and $200 \mathrm{mg} / \mathrm{kg}$ after $120 \mathrm{~min}$ exhibited significant analgesic activity by tail immersion method, in comparison to 0 . reticulata. However, with hot plate method, anthocyanin of $O$. reticulata produced a significant analgesic activity even at lower doses (50 and $100 \mathrm{mg} / \mathrm{kg})$ after $120 \mathrm{~min}$. However, in writhing test, theepurified anthocyanin of $O$. aspera significantly stopped the number of writhes at a dose of $200 \mathrm{mg} / \mathrm{kg}$ and also by the anthocyanin of O. reticulata. In the evaluation of anti-inflammatory effect using plethysmometer, anthocyanin at doses of 100,150 and $200 \mathrm{mg} / \mathrm{kg}$ started producing anti-inflammatory effect after $30 \mathrm{~min}$, which lasted until $120 \mathrm{~min}$.

Conclusion: It is concluded from the present study that the purified anthocyanin of Osbeckia possesses potent analgesic and anti-inflammatory activities.

Keywords: Osbeckia, Purified anthocyanin, In vitro culture, Analgesic activity, Anti-inflammatory activity, Acetic acid, Carrageenan.

(c) 2019 The Authors. Published by Innovare Academic Sciences Pvt Ltd. This is an open access article under the CC BY license (http://creativecommons. org/licenses/by/4. 0/) DOI: http://dx.doi.org/10.22159/ajpcr.2019.v12i1.27402

\section{INTRODUCTION}

Melastomataceae species are mostly dominated along the tropic and subtropic regions, with approximately 4000 species distributed all over the world. The genus Osbeckia of Melastomataceae comprises 31 species. In India, it is represented by 26 species. Kerala, particularly, with a tropical climate abode 12 species and many of which were used by natives in folk medicine [1].

Osbeckia reticulata and Osbeckia aspera were two closely related plant species distributed along the hill tracks of Kerala. They are referred locally in Sri Lanka as Heen Bovitiya and were used in traditional medicine for the alleviation of jaundice or other liver diseases [2].

Herbals were well known for their biological effects including antioxidant, antitumor, antimutagenic, and antimicrobial features. From the prehistoric periods, plant-based crude drugs have been used in conventional medicine for the treatment of different diseases. Many phytochemicals isolated from plants showed protection against different diseases such as cardiovascular, cancer, and inflammation. Globally, many medicinal plants are of immense research interest in the search of novel drugs for curing many disorders without any side effects.

Anthocyanins are water-soluble natural pigments belonging to flavonoid group of dark-colored phenols and common in fruits and vegetables. Due to their wide distribution in plants, dietary consumption of anthocyanin is relatively high compared to other polyphenols. Anthocyanins possess multifaceted medicinal properties and also the active molecules in many of the herbal folk drugs. In vitro and in vivo data, animal model, and clinical trials in various organisms suggest their antioxidant, antidiabetic, antihyperlipidemic, anti-inflammatory, anticarcinogenic, antiulcer, and preventive activities against heart prone diseases [3]. In addition, they show chemotherapeutic and cardio-, hepato-, and neuroprotective activities. In the natural diet, they are absorbed by the stomach and intestinal cells and were also detected in the plasma. These unique features of anthocyanins reveal their health benefits against chronic disorders [4]. Anthocyanins function as balancer of oxidative and antioxidative events, thus safeguarding the health. Black currant contains rich amounts of anthocyanins, with remarkable antioxidant and anti-inflammatory effects. Research outputs suggest that anthocyanins prevent oxidative stress and inflammation-induced cancers [5]. In this scenario, the aim of this study is to evaluate the anti-inflammatory efficacy of purified anthocyanins isolated from the in vitro callus cultures of $O$. reticulata and $O$. aspera using animal models.

\section{METHODS}

Plant material

Osbeckia sps. for the present study was collected from different parts of Idukki and Kottayam districts of Kerala. O. aspera is a perennial 
shrub, propagated naturally by vegetative means and through seeds. 0 . reticulata is a small tree frequently seen in temperate habitats of high-altitude regions. Identification of the species was done by referring authentic floras and confirmed by herbaria of Jawaharlal Nehru Tropical Botanical Garden and Research Institute, Palode, Trivandrum.

\section{In vitro culture}

The collected plantlets were cultivated in the greenhouse of the college botanical garden. Stem and leaf segments from healthy, disease-free plants were used as explants. The explants were subjected to surface sterilization using $10 \%$ Teepol solution followed by rinsing in tap water for $60 \mathrm{~min}$. Then, the stem cuttings were immersed in ethanol $70 \%$ (v/v) for $30 \mathrm{~s}$ and, finally, mercuric chloride or sodium hypochlorite. Ethanol treatment was found to damage the leaves. In the last step, explants were washed thoroughly in distilled water.

After sterilization, nodal segments $(2-3 \mathrm{~cm})$ were used for multiple shoot induction and internodal and leaf cuttings were used for direct organogenesis and callus induction. The explants were transferred to MS culture medium supplemented with various phytohormones, besides the control group (without growth regulators). During the entire process of in vitro culture, the plantlets were kept in $2.5 \mathrm{~cm} \times 15 \mathrm{~cm}$ test tubes. The MS culture media were supplemented with vitamins, sucrose $(30 \mathrm{~g} / \mathrm{L})$, and agar $(7 \mathrm{~g} / \mathrm{L})[6]$. The culture medium $\mathrm{pH}$ was adjusted to $5.7 \pm 0.1$. Media were sterilized by autoclaving for $15 \mathrm{~min}$ at $120^{\circ} \mathrm{C}$ and $15 \mathrm{lbs}$ of pressure. All experiments were conducted in a completely randomized design.

Anthocyanin was estimated by the protocol of Sutharut and Sudarat [7]. The absorbance was read at 510 and $700 \mathrm{~nm}$ against distilled water as blank.

Aqueous acidified methanol and ethanol were commonly used for the extraction of anthocyanins. Different absorbents such as silica gel, Amberlite IRC 80, Amberlite IR 120, DOWEX 50WX8, Amberlite XAD4, and Amberlite XAD7 were examined for the purification of anthocyanins.

\section{Animals}

Swiss albino mice of both sexes weighing 25-30 g were used in the study. Animals were kept and maintained under laboratory condition of temperature $23 \pm 1^{\circ} \mathrm{C}$ with $12 \mathrm{~h} / 12 \mathrm{~h}$ light and dark cycles and were allowed free access to food and water as per the standard protocols.

\section{Acute oral toxicity study}

An acute toxicity test was performed as per the Organization of Economic Co-operation and Development (OECD) guideline 420 [8]. Mice of both the sexes, aged 6-8 weeks old, were used. Purified anthocyanins of 0 . reticulata and O. aspera were dissolved in $10 \%$ Tween 20 and administered orally (only once) at a single dose of 3000 $\mathrm{mg} / \mathrm{kg}$ at a rate of $20 \mathrm{~mL} / \mathrm{kg}$ to the animals, whereas the control group received only $10 \%$ Tween 20 as a vehicle. After administration, mice were observed for $24 \mathrm{~h}$, with special attention given to the first $4 \mathrm{~h}$ and once daily further for 14 days. The animals were weighed, and visual observations for mortality, behavioral pattern (salivation, fur, lethargy, and sleep), changes in physical appearance, injury, pain, and signs of illness were conducted once daily during the entire period.

\section{Subchronic oral toxicity study}

The subchronic toxicity test was performed following the method described by the OECD guideline 408 [9]. Animals of both the sexes were randomly assigned into five groups: A control group and four treatment groups $(\mathrm{n}=20 ; 10$ males and 10 females). Purified anthocyanins of $O$. reticulata and $O$. aspera were dissolved in $10 \%$ Tween 20 and administered orally on daily basis for 90 days at single doses of 50,100, 250, and $1000 \mathrm{mg} / \mathrm{kg}$, while the control group received only 10\% Tween 20 in distilled water. An additional group was devised as the satellite group to observe the reverse sign of any toxicity. The satellite group was orally administered with the extract at a daily dose of $1000 \mathrm{mg} / \mathrm{kg} /$ day for 90 days, and there was no further treatment for the following 28 days before termination of the study. The extract was freshly prepared with vehicle on daily basis. The mice were weighed, and visual observations for mortality, behavioral pattern, changes in physical appearance, injury, pain, and signs of illness were recorded once daily during the study period.

\section{Anti-inflammatory activity}

Anti-inflammatory potentiality of the purified anthocyanin of Osbeckia species was analyzed by carrageenan method [10]. Edema was induced by subplantar injection of $0.1 \mathrm{~mL}$ of $1 \%$ carrageenan solution in $0.9 \%$ saline solution into the left hind paw of the mice an hour after oral administration of silymarin (50 mg/ $\mathrm{kg} \mathrm{p.o})$, indomethacin (10 mg/kg p.o), or anthocyanin (150 and $200 \mathrm{mg} / \mathrm{kg}$ p.o). Control was administered with saline water only. Paw volume was measured after $1,2,3,4,5,6,7$, and $8 \mathrm{~h}$ of carrageenan treatment by means of volume displacement method using plethysmometer. The difference between initial and after treatment paw volumes indicated the degree of inflammation. Edema was expressed as a percentage increase in paw volume due to carrageenan administration referred to the non-injected paw. The mean increase in paw volume of each group was calculated and compared with the control and standard groups.

\section{Analgesic activity \\ Tail flick method}

For the tail flick method, pain was induced by providing radiant heat on the tail of the mice $5 \mathrm{~cm}$ away from the tip of the tail (using tail flick analgesic instrument). Mice were held loosely in a towel during the test. Reaction time was noted as the interval between exposing the tail to the light beam and the withdrawal of the tail. A cutoff time of $20 \mathrm{~s}$ was imposed as a protection against tissue damage [11]. The test was done at $0,0.5,1,1.5,2,3,4,6$, and $8 \mathrm{~h}$. After $24 \mathrm{~h}$, the mice were tested again for any remaining activity. The change in latency time was calculated as $\mathrm{T}-\mathrm{T} 0$ (where $\mathrm{T} 0$ is the latency at zero time).

\section{Hot plate method}

Evaluation of analgesic activity of the anthocyanin was also carried out using hot plate method [12]. The mice were placed on a hot plate maintained at $55^{\circ} \mathrm{C}$ within the restrainer. The reaction time (in seconds) or latency period was determined as the time taken for the rats to react to the thermal pain by licking their paws or jumping. The reaction time was recorded before $0 \mathrm{~min}$ and at 15, 30, 45, and $60 \mathrm{~min}$ after the administration of the treatments. The maximum reaction time was fixed at $45 \mathrm{~s}$ to prevent any injury to the tissues of the paws. If the reading exceeds $45 \mathrm{~s}$, it would be considered as maximum analgesia. The maximum possible analgesia was calculated as follows:

$$
\mathrm{MPA}=\frac{\text { Reaction } \text { time for treatment }- \text { Reaction time for saline }}{15 \mathrm{~s}-\text { Reaction time for saline }} \times 100
$$

\section{Analgesy meter}

Analgesic potential was determined by keeping the left hind paw of the rat on a plinth under a cone-shaped pusher of the analgesy meter. It generates a linearly increasing mechanical force or pressure on hind paw. As the applied pressure increases, it gets to a point where the animal struggles to free its paw. The strength at which each rat withdrew its paw was recorded and considered as indicative of pain. The reaction strength of each mouse was determined before and after drug treatment in a regular interval of 30,60, and 120 min after treatment with silymarin $(50 \mathrm{mg} / \mathrm{kg} \mathrm{p.o})$ and anthocyanin $(50,100$, and $200 \mathrm{mg} / \mathrm{kg}$ p.o). Stimulus was terminated, and force threshold was read in grams.

\section{Acetic acid-induced writhing}

The peripheral nociceptive activity of anthocyanin was determined by the acetic acid abdominal constriction test. The writhes were induced by the intraperitoneal injection of $1 \%$ acetic acid $(10 \mathrm{ml} / \mathrm{kg})$. The number of writhes (muscular contractions) was counted 5 min after 
acetic acid injection over $20 \mathrm{~min}$. The number of writhes in each group was compared with the control and the percentage reduction of writhes count was calculated as follows:

Inhibition (\%)=Mean number of writhes (control)-Mean number of writhes (test)/Mean number of writhes (control) $\times 100$

\section{Statistical analysis}

SPSS version 20.0 statistic software was used for the entire analysis. Results were expressed as mean \pm standard deviation. Student's t-test was carried out to compare the results of control and anthocyanintreated groups. Significant was recorded either $\mathrm{p}<0.05$ or $\mathrm{p}<0.01$.

\section{RESULTS}

In vitro culture and purification of anthocyanins

Anthocyanin-producing callus cultures were established on MS medium fortified with various combinations of phytohormones and sucrose. Callus formation in $O$. aspera was optimal on cultures containing $0.5 \mathrm{mg} / \mathrm{L}$ of $2,4-\mathrm{D}$, and $0.5 \mathrm{mg} / \mathrm{L}$ 6-benzylaminopurine (BA). In 0. reticulata, callus was ideal in the presence of $1.2 \mathrm{mg} / \mathrm{L} \mathrm{BA}$ and $1.4 \mathrm{mg} / \mathrm{L}$ naphthalene acetic acid (NAA). The same hormonal combination on extended treatments turned the white friable callus into red compact callus. Combination of either of the cytokinins along with both NAA and IBA and higher concentrations of sucrose in the medium (2-2.5 fold) induced the synthesis of anthocyanin in the friable callus, and anthocyanin was extracted from the callus using a mixture of ethanol and water in the ratio 70:30 acidified with $1 \% \mathrm{HCl}$. Anthocyanins were isolated and purified by column chromatography in silica gel and subsequently using amberlite. Amberlite XAD7HP was most effective because of its highest capacity and desorption ratio. Liquid chromatography-tandem mass spectrometry analysis of the purified anthocyanin from 0 . aspera and 0 . reticulata showed the presence of malvidin-3-diglucoside, delphinidin, cyanidin aglycone, and peonidin.
Acute oral toxicity

Purified anthocyanin of Osbeckia species at a dose of $3000 \mathrm{mg} / \mathrm{kg}$ revealed no adverse visible effect on the behavioral responses of the tested animals up to 14 days. No visual changes in the skin, fur, eyes mucous layer, tremors, salivation, and diarrhea of the mice. Similarly, no mortality or the loss of body weight in the mice was noticed at the tested dose (control $=28 \mathrm{~g}$ and treated $=28.4 \mathrm{~g}$ ). No remarkable differences were seen in the relative organ weights in the rats (Table 1). Meanwhile, significant variations $(\mathrm{p}<0.05)$ were noticed in the liver and spleen in the treated mice as compared with the control group. Thus, $\mathrm{LD}_{50}$ of anthocyanin of Osbeckia species was fixed as $3000 \mathrm{mg} / \mathrm{kg}$.

\section{Subchronic oral toxicity}

Daily oral administration of different concentrations of anthocyanin from Osbeckia species for 90 days did not induced any significant toxicity in the animals of both sexes, including the tested dose at $1000 \mathrm{mg} / \mathrm{kg}$ body weight. No death syndromes or visual clinical symptoms were noticed in any mice throughout the study periods. Physical features of the treated mice throughout the entire study period did not show any signs of toxicity in their skin, fur, eyes, mucus layer, or behavioral changes, diarrhea, tremors, salivation, sleep, and coma. Normal body weight gains were observed during the study period compared to the control group (control $=29.5 \mathrm{~g}$ and treated groups ranged from 29.7 to $29.84 \mathrm{~g}$ ). No abnormal gross findings were noticed in the necropsies of any of the mice. No significant variations were seen in food and water intake of the tested mice as compared to the control (Table 2).

\section{Anti-inflammatory analysis \\ Carrageenan-induced paw edema assay}

Carrageenan-induced paw edema method was used to detect the antiinflammatory effect of purified anthocyanin of Osbeckia species, and the results are narrated in Table 3. Purified anthocyanin of Osbeckia species exhibited inhibition of edema at the doses of 150 and $200 \mathrm{mg} / \mathrm{kg}$ effectively as compared to control but less as compared to the standards.

Table 1: Mice treated with purified anthocyanin $(3000 \mathrm{mg} / \mathrm{kg})$ from 0 . aspera and 0 . reticulata in terms of weight of organs related with acute oral toxicity analysis

\begin{tabular}{|c|c|c|c|c|c|c|c|c|}
\hline \multirow[t]{3}{*}{ Organs } & \multicolumn{4}{|l|}{ O. aspera } & \multicolumn{4}{|c|}{ o. reticulata } \\
\hline & \multicolumn{2}{|l|}{ Control } & \multicolumn{2}{|l|}{ Treated } & \multicolumn{2}{|l|}{ Control } & \multicolumn{2}{|l|}{ Treated } \\
\hline & Male & Female & Male & Female & Male & Female & Male & Female \\
\hline Heart & $0.43 \pm 0.03$ & $0.44 \pm 0.01$ & $0.42 \pm 0.01$ & $0.41 \pm 0.01$ & $0.43 \pm 03$ & $0.44 \pm 0.01$ & $0.41 \pm 0.04$ & $0.40 \pm 0.03$ \\
\hline Liver & $3.61 \pm 0.09$ & $3.65 \pm 0.05$ & $3.55 \pm 0.06$ & $3.61 \pm 0.07$ & $3.61 \pm 0.09$ & $3.65 \pm 0.05$ & $3.52 \pm 0.09$ & $3.60 \pm 0.05$ \\
\hline Spleen & $0.35 \pm 0.01$ & $0.41 \pm 0.02$ & $0.30 \pm 0.03$ & $0.36 \pm 0.04$ & $0.35 \pm 0.01$ & $0.41 \pm 0.02$ & $0.29 \pm 0.02$ & $0.34 \pm 0.03$ \\
\hline Kidneys & $0.85 \pm 0.06$ & $0.89 \pm 0.08$ & $0.83 \pm 0.05$ & $0.87 \pm 0.02$ & $0.85 \pm 0.06$ & $0.89 \pm 0.08$ & $0.81 \pm 0.07$ & $0.86 \pm 0.06$ \\
\hline Lungs & $0.69 \pm 0.08$ & $0.78 \pm 0.03$ & $0.68 \pm 0.04$ & $0.77 \pm 0.07$ & $0.69 \pm 0.08$ & $0.78 \pm 0.03$ & $0.67 \pm 0.08$ & $0.75 \pm 0.02$ \\
\hline
\end{tabular}

Values \pm SD; $\mathrm{P}<0.05$. SD: Standard deviation, O. aspera: Osbeckia aspera, O. reticulate: Osbeckia reticulata

Table 2: Mice treated with different concentrations of purified anthocyanin from 0 . aspera and 0 . reticulata in terms of weight of organs related with subchronic oral toxicity analysis

\begin{tabular}{|c|c|c|c|c|c|c|c|c|c|c|}
\hline & \multicolumn{5}{|l|}{ Male } & \multicolumn{5}{|l|}{ Female } \\
\hline & Control & 50 & 100 & 250 & 1000 & Control & 50 & 100 & 250 & 1000 \\
\hline \multicolumn{11}{|c|}{ Osbeckia aspera } \\
\hline Heart & $0.44 \pm 0.07$ & $0.42 \pm 0.02$ & $0.41 \pm 0.05$ & $0.43 \pm 0.03$ & $0.44 \pm 0.06$ & $0.46 \pm 0.05$ & $0.44 \pm 0.04$ & $0.44 \pm 0.04$ & $0.43 \pm 0.03$ & $0.43 \pm 0.05$ \\
\hline Liver & $2.96 \pm 0.04$ & $3.01 \pm 0.01$ & $3 \pm 0.2$ & $2.95 \pm 0.08$ & $2.96 \pm 0.02$ & $3.11 \pm 0.01$ & $3.07 \pm 0.05$ & $3.09 \pm 0.21$ & $3.1 \pm 0.13$ & $3.1 \pm 0.11$ \\
\hline Spleen & $0.29 \pm 0.02$ & $0.27 \pm 0.03$ & $0.27 \pm 0.08$ & $0.26 \pm 0.03$ & $0.29 \pm 0.01$ & $0.36 \pm 0.04$ & $0.34 \pm 0.05$ & $0.33 \pm 0.07$ & $0.35 \pm 0.04$ & $0.35 \pm 0.05$ \\
\hline Kidneys & $0.72 \pm 0.04$ & $0.74 \pm 0.02$ & $0.73 \pm 0.02$ & $0.73 \pm 0.04$ & $0.71 \pm 0.04$ & $0.75 \pm 0.07$ & $0.72 \pm 0.02$ & $0.73 \pm 0.03$ & $0.74 \pm 0.02$ & $0.74 \pm 0.06$ \\
\hline \multicolumn{11}{|c|}{ Osbeckia reticulata } \\
\hline Heart & $0.44 \pm 0.03$ & $0.37 \pm 0.04$ & $0.36 \pm 0.01$ & $0.37 \pm 0.08$ & $0.38 \pm 0.04$ & $0.46 \pm 0.08$ & $0.40 \pm 0.07$ & $0.41 \pm 0.02$ & $0.41 \pm 0.01$ & $0.43 \pm 0.02$ \\
\hline Liver & $2.96 \pm 0.30$ & $3.1 \pm 0.15$ & $3.0 \pm 0.02$ & $2.87 \pm 0.25$ & $2.9 \pm 0.4$ & $3.11 \pm 0.14$ & $3.05 \pm 0.09$ & $3.04 \pm 0.03$ & $3.02 \pm 0.17$ & $3.05 \pm 0.12$ \\
\hline Spleen & $0.29 \pm 0.06$ & $0.23 \pm 0.03$ & $0.23 \pm 0.04$ & $0.25 \pm 0.05$ & $0.25 \pm 0.09$ & $0.36 \pm 0.07$ & $0.30 \pm 0.07$ & $0.33 \pm 0.02$ & $0.32 \pm 0.03$ & $0.32 \pm 0.01$ \\
\hline Kidneys & $0.72 \pm 0.03$ & $0.77 \pm 0.07$ & $0.75 \pm 0.09$ & $0.75 \pm 0.01$ & $0.73 \pm 0.02$ & $0.75 \pm 0.05$ & $0.72 \pm 0.02$ & $0.71 \pm 0.03$ & $0.70 \pm 0.06$ & $0.72 \pm 0.07$ \\
\hline Lungs & $0.9 \pm 0.03$ & $0.84 \pm 0.05$ & $0.83 \pm 0.07$ & $0.86 \pm 0.02$ & $0.85 \pm 0.21$ & $0.79 \pm 0.06$ & $0.73 \pm 0.01$ & $0.74 \pm 0.02$ & $0.74 \pm 0.08$ & $0.75 \pm 0.02$ \\
\hline
\end{tabular}

Values were mean $\pm S D ; p<0.01$. SD: Standard deviation 
Table 3: Anti- inflammatory potential on carrageenan-induced paw edema in Wistar albino mice by purified anthocyanin of o. aspera $(\mathrm{OA})$ and 0 . reticulata $(\mathrm{OR})$

\begin{tabular}{|c|c|c|c|c|c|c|c|c|}
\hline \multirow[t]{2}{*}{ Group } & \multirow{2}{*}{$\begin{array}{l}\text { Initial paw } \\
\text { volume }(\mathrm{mm})\end{array}$} & \multicolumn{7}{|c|}{ Paw volume after induction (mm) } \\
\hline & & $\mathbf{1}^{\text {st }} \mathbf{h}$ & $2^{\text {st }} \mathbf{h}$ & $3^{\text {st }} \mathbf{h}$ & $4^{\text {st }} \mathrm{h}$ & $5^{\text {st }} \mathbf{h}$ & $6^{\text {st }} h$ & $\mathbf{8}^{\text {st }} \mathbf{h}$ \\
\hline Group I saline & 1.20 & 1.74 & 1.97 & 2.26 & 2.28 & 1.95 & 1.86 & 1.73 \\
\hline Group II carrageenan & 1.20 & 1.94 & 2.42 & 2.55 & 2.67 & 2.72 & 2.83 & 2.95 \\
\hline Group III indomethacin (10 mg/kg) & 1.21 & 1.91 & 2.18 & 1.59 & 1.45 & 1.22 & 1.22 & 1.20 \\
\hline Group IV OA $150 \mathrm{mg} / \mathrm{kg}$ & 1.21 & 2.03 & 2.19 & 2.02 & 1.45 & 1.36 & 1.27 & 1.24 \\
\hline Group V OA 200 mg/kg & 1.20 & 1.92 & 2.15 & 1.48 & 1.39 & 1.25 & 1.23 & 1.21 \\
\hline Group VI OR 150 mg/kg & 1.19 & 1.98 & 2.2 & 1.65 & 1.58 & 1.44 & 1.37 & 1.23 \\
\hline Group VII OR 200 mg/kg & 1.21 & 1.88 & 2.05 & 1.53 & 1.45 & 1.28 & 1.25 & 1.22 \\
\hline Group VIII Silymarin (50 mg/kg) & 1.21 & 1.90 & 1.87 & 1.76 & 1.68 & 1.22 & 1.21 & 1.2 \\
\hline
\end{tabular}

Values were mean \pm SD; $<<0.01$. OA: Osbeckia aspera, OR: Osbeckia reticulate, SD: Standard deviation

Table 4: Analgesic effect of different doses of Ac of OA and OR by tail flick method in mice

\begin{tabular}{|c|c|c|c|c|c|c|c|c|c|c|}
\hline \multirow[t]{2}{*}{ Treat } & \multicolumn{10}{|c|}{ Reaction time (s, mean \pm SD) } \\
\hline & $\mathbf{0 ~ h}$ & $0.5 \mathrm{~h}$ & $1.0 \mathrm{~h}$ & $1.30 \mathrm{~h}$ & $2 \mathrm{~h}$ & $3 \mathbf{h}$ & $4 \mathrm{~h}$ & $6 \mathrm{~h}$ & $8 \mathbf{h}$ & $24 \mathrm{~h}$ \\
\hline \multicolumn{11}{|l|}{$\mathrm{OA}(\mathrm{mg} / \mathrm{kg})$} \\
\hline Control & $2.78 \pm 0.1$ & $2.82 \pm 0.18$ & $2.8 \pm 0.14$ & $2.86 \pm 0.23$ & $2.92 \pm 0.2$ & $2.88 \pm 0.04$ & $2.90 \pm 0.28$ & $2.82 \pm 0.23$ & $3 \pm 0.28$ & $2.9 \pm 0.25$ \\
\hline OA Ac 50 & $3.14 \pm 0.1$ & $3.24 \pm 0.11$ & $3.88 \pm 0.8$ & $4.76 \pm 0.7$ & $4.8 \pm 1.15$ & $5.24 \pm 1.3$ & $4.76 \pm 1.1$ & $3.68 \pm 0.9$ & $3.4 \pm 0.14$ & $2.85 \pm 0.07$ \\
\hline OA Ac 100 & $2.87 \pm 0.1$ & $3.51 \pm 0.24$ & $4.20 \pm 0.7$ & $5.84 \pm 0.6$ & $7.09 \pm 0.8$ & $7.46 \pm 0.8$ & $6.44 \pm 0.8$ & $5.63 \pm 0.6$ & $5.15 \pm 0.7$ & $4 \pm 0.14$ \\
\hline OA Ac 150 & $2.65 \pm 0.1$ & $3.63 \pm 0.43$ & $4.68 \pm 0.5$ & $6.15 \pm 0.9$ & $7.23 \pm 0.6$ & $8.25 \pm 0.9$ & $7.53 \pm 0.7$ & $6.15 \pm 0.6$ & $5.7 \pm 0.1$ & $4.67 \pm 0.2$ \\
\hline OA Ac 200 & $2.89 \pm 0.1$ & $4.47 \pm 0.4$ & $4.84 \pm 0.4$ & $6.79 \pm 0.6$ & $7.81 \pm 0.5$ & $10.07 \pm 1$ & $8.1 \pm 1.07$ & $6.8 \pm 1.26$ & $6.25 \pm 0.7$ & $5.05 \pm 0.2$ \\
\hline \multicolumn{11}{|l|}{ OR (mg/kg) } \\
\hline OR Ac 50 & $3.04 \pm 0.2$ & $3.12 \pm 0.04$ & $345 \pm 0.12$ & $4.3 \pm 0.09$ & $4.5 \pm 0.22$ & $5.00 \pm 0.34$ & $4.4 \pm 0.08$ & $3.5 \pm 0.2$ & $3.2 \pm 0.07$ & $2.60 \pm 0.25$ \\
\hline OR Ac 100 & $2.5 \pm 0.03$ & $3.00 \pm 0.11$ & $3.6 \pm 0.3$ & $4.8 \pm 0.4$ & $6.1 \pm 0.8$ & $6.7 \pm 0.00$ & $5.8 \pm 0.8$ & $4.9 \pm 0.00$ & $4.6 \pm 0.00$ & $3.8 \pm 0.00$ \\
\hline OR Ac 150 & $2.49 \pm 0.0$ & $3.2 \pm 0.00$ & $4.00 \pm 0.0$ & $5.5 \pm 0.00$ & $6.7 \pm 0.6$ & $7.3 \pm 0.0$ & $6.8 \pm 0.0$ & $6.00 \pm 0.00$ & $5.4 \pm 0.1$ & $4.30 \pm 0.2$ \\
\hline OR Ac 200 & $2.6 \pm 0.1$ & $3.8 \pm 0.4$ & $4.3 \pm 0.00$ & $5.92 \pm 0.0$ & $6.9 \pm 0.5$ & $8.2 \pm 0.00$ & $7.0 \pm 1.07$ & $6.3 \pm 0.00$ & $5.8 \pm 0.00$ & $5.00 \pm 0.2$ \\
\hline Silymarin 50 & $2.81 \pm 0.1$ & $11.31 \pm 0.1$ & $9.30 \pm 1.3$ & $7.61 \pm 0.7$ & $6.23 \pm 0.4$ & $4.16 \pm 0.7$ & $3.77 \pm 0.46$ & $3.44 \pm 0.39$ & $3.15 \pm 0.21$ & $3.0 \pm 0.14$ \\
\hline
\end{tabular}

Values were mean \pm SD; $<<0.01$. Ac: Anthocyanin, OA: Osbeckia aspera, OR: Osbeckia reticulate, SD: Standard deviation

Table 5: Analgesic activity of Ac of OA and OR evaluated by analgesy meter in mice

\begin{tabular}{llllll}
\hline \multicolumn{5}{c}{$\begin{array}{l}\text { Dose } \\
\text { (mg kg) }\end{array}$} & \multicolumn{4}{l}{ Reaction time (s) } \\
\cline { 3 - 6 } & & $\mathbf{0} \mathbf{~} \mathbf{n i n}$ & $\mathbf{3 0} \mathbf{~ m i n}$ & $\mathbf{6 0} \mathbf{~ m i n}$ & $\mathbf{1 2 0} \mathbf{~ m i n}$ \\
\hline OA & 100 & $1.67 \pm 0.12$ & $12.7 \pm 0.03$ & $14.5 \pm 0.01$ & $2.45 \pm 0.01$ \\
& 150 & $2.5 \pm 0.1$ & $4.6 \pm 0.1$ & $18.7 \pm 0.23$ & $10.5 \pm 0.04$ \\
& 200 & $1.87 \pm 0.01$ & $8.55 \pm 0.21$ & $9.8 \pm 0.21$ & $5.78 \pm 0.03$ \\
OR & 100 & $1.54 \pm 0.00$ & $10.57 \pm 0.2$ & $13.2 \pm 0.18$ & $3.65 \pm 0.02$ \\
& 150 & $2.34 \pm 0.12$ & $4.58 \pm 0.02$ & $16.2 \pm 0.31$ & $9.44 \pm 0.13$ \\
& 200 & $1.97 \pm 0.03$ & $7.92 \pm 0.01$ & $10.4 \pm 0.02$ & $6.47 \pm 0.09$ \\
Silymarin & 50 & $2.47 \pm 0.02$ & $8.67 \pm 0.02$ & $8.59 \pm 0.01$ & $6.98 \pm 0.14$ \\
\hline
\end{tabular}

Values mean \pm SD; $<<0.05$. Ac: Anthocyanin, OA: Osbeckia aspera, OR: Osbeckia reticulate, SD: Standard deviation

The anthocyanin of Osbeckia species displayed optimal activities from $5^{\text {th }} \mathrm{h}$ onward. Among the two species, anthocyanin of $O$. aspera showed significant anti-inflammatory activity at a dose of $200 \mathrm{mg} / \mathrm{kg}$ and was commendable than that of the standard drug indomethacin.

\section{Analgesic analysis}

Tail immersion protocol

The results of the analgesic activity of the purified anthocyanin of Osbeckia species were showed in Table 4. Control group of mice (injected by vehicle) did not show any remarkable variations in the reaction time on tail flick throughout the study period. Purified anthocyanin of Osbeckia species (50,100,150, and $200 \mathrm{mg} / \mathrm{kg}$ ) revealed a remarkable and concentration-dependent enhancing in the latency time as compared to the control rats. The maximum reaction time for silymarin (standard) was $11.31 \mathrm{~s}$ reached at $30 \mathrm{~min}$, which returns to normal after $3 \mathrm{~h}$ (4.16s). Meanwhile, the maximum activity of purified anthocyanin of 0 . aspera appeared after $3 \mathrm{~h}(5.24,7.46,8.25$, and $10.07 \mathrm{~s}$ for $50,100,150$, and $200 \mathrm{mg} / \mathrm{kg}$ doses, respectively) (Table 4).
These increases in latencies remain significant after $8 \mathrm{~h}$ and maintained even after $24 \mathrm{~h}$. The relative activity of anthocyanin of 0 . reticulata with respect to silymarin in tail flick test is shown in Table 4. Table 4 demonstrates that, after $3 \mathrm{~h}$, all doses $(50,100,150$, and $200 \mathrm{mg} / \mathrm{kg}$ ) of anthocyanin were equally effective as silymarin in relative activity. The difference in the activity between anthocyanin and silymarin after $3 \mathrm{~h}$ (until $8 \mathrm{~h}$ ) was statistically significant. Silymarin was more potent between 0 and $2 \mathrm{~h}$. On the other hand, anthocyanin reached its peak activity after $3 \mathrm{~h}$ indicating a slow onset of action, but its analgesic activity extended remarkably even after $8 \mathrm{~h}$. By comparing the coverage of analgesia by time, the anthocyanin $200 \mathrm{mg} / \mathrm{kg}$ was more significant than that of silymarin with peak response (change in latency). Similarly, the other doses $(50,100$, and $150 \mathrm{mg} / \mathrm{kg})$ also showed greater coverage of analgesia and was comparable to that of silymarin.

\section{Analgesy meter method}

Results of analgesic activity of purified anthocyanin of Osbeckia species measured by analgesy meter method are given in Table 5. The purified anthocyanin of Osbeckia sps. exhibited good analgesic effect up to $120 \mathrm{~min}$ with the concentrations of 100,150 , and $200 \mathrm{mg} / \mathrm{kg}$ as compared to control. Further, at the doses of 150 and $200 \mathrm{mg} / \mathrm{kg}$, it showed remarkable analgesic effect comparable with that of standard, silymarin. The maximum analgesic effect was achieved at a dose of $200 \mathrm{mg} / \mathrm{kg}$ after $120 \mathrm{~min}$. The 0 . aspera anthocyanin extract showed good analgesic effect at the doses of 150 and $200 \mathrm{mg} / \mathrm{kg}$, as compared to $O$. reticulata, control, and standard drug. Similarly, maximum activity for 0 . reticulata was also noted at the concentrations of 150 and $200 \mathrm{mg} / \mathrm{kg}$ than at lower doses at $120 \mathrm{~min}$.

\section{Hot plate method}

The results of the analgesic effect of the purified anthocyanin of Osbeckia sps. using hot plate method are presented in Table 6. The results showed that there was no significant difference on the thermal stimulus in mice treated with normal saline (negative control) throughout the 
Table 6: Analgesic effect of the purified anthocyanin of $\mathrm{OA}$ and $\mathrm{OR}$

\begin{tabular}{|c|c|c|c|c|c|}
\hline \multirow[t]{2}{*}{ Treatments } & \multicolumn{5}{|c|}{ Reaction time (s) $($ mean \pm SD) } \\
\hline & $0 \mathrm{~min}$ & $15 \mathrm{~min}$ & $30 \mathrm{~min}$ & $45 \mathrm{~min}$ & $60 \mathrm{~min}$ \\
\hline Control (normal saline) & $30.75 \pm 5.3$ & $20.5 \pm 4.7$ & $30.5 \pm 4.7$ & $24.8 \pm 6.7$ & $24.3 \pm 6.2$ \\
\hline Sodium salicylate & $32.4 \pm 4.9$ & $27.2 \pm 4.4$ & $31.2 \pm 2.1$ & $34.8 \pm 2.8$ & $31.3 \pm 1.6$ \\
\hline OA $150 \mathrm{mg} / \mathrm{kg}$ & $30.8 \pm 4.8$ & $27.7 \pm 2.7$ & $24.5 \pm 3.8$ & $27.7 \pm 3.2$ & $26.1 \pm 4.6$ \\
\hline OA $200 \mathrm{mg} / \mathrm{kg}$ & $31 \pm 5.8$ & $33.6 \pm 2.1$ & $38.5 \pm 3.0$ & $37 \pm 3.9$ & $36.1 \pm 4$ \\
\hline OR $150 \mathrm{mg} / \mathrm{kg}$ & $28.8 \pm 2.3$ & $29.7 \pm 2.4$ & $29 \pm 3.1$ & $29 \pm 1.2$ & $29 \pm 5.6$ \\
\hline OR $200 \mathrm{mg} / \mathrm{kg}$ & $30 \pm 3.6$ & $31 \pm 3.8$ & $33 \pm 5.8$ & $33.8 \pm 6.2$ & $34 \pm 4$ \\
\hline Silymarin $50 \mathrm{mg} / \mathrm{kg}$ & $30 \pm 1.6$ & $32 \pm 7.7$ & $35 \pm 2.7$ & $35.9 \pm 1.92$ & $36 \pm 2$ \\
\hline
\end{tabular}

Values mean \pm SD; $\mathrm{p}<0.01$. OA: Osbeckia aspera, OR: Osbeckia reticulate, SD: Standard deviation

Table 7: Analgesic activity of anthocyanin by acetic acid-induced writhing in mice

\begin{tabular}{lll}
\hline Group & $\begin{array}{l}\text { Number } \\
\text { of writhes } \\
\text { (mean } \pm \text { SD) }\end{array}$ & $\begin{array}{l}\text { Reduction } \\
\text { in writhes } \\
\text { count (\%) }\end{array}$ \\
\hline Control (acetic acid 1\%) & $57.8 \pm 6.5$ & 0 \\
Silymarin 50mg/kg & $12.6^{* *} \pm 2.9$ & 78.2 \\
Diclofenac 10mg/kg & $7.7^{* *} \pm 0.8$ & 86.68 \\
OA $150 \mathrm{mg} / \mathrm{kg}$ & $20.4^{* *} \pm 3$ & 64.7 \\
OA $200 \mathrm{mg} / \mathrm{kg}$ & $10.2^{* *} \pm 3$ & 82.4 \\
OR $150 \mathrm{mg} / \mathrm{kg}$ & $24.4^{* *} \pm 2.4$ & 57.8 \\
OR $200 \mathrm{mg} / \mathrm{kg}$ & $14.5^{* *} \pm 3$ & 74.9 \\
\hline
\end{tabular}

Values mean \pm SD; $\mathrm{p}<0.05$. OA: Osbeckia aspera, OR: Osbeckia reticulate,

SD: Standard deviation

60-min observation. There was no increase in reaction time at all time points compared to baseline values $(0 \mathrm{~min})$ within the same treatment groups. In comparison to the saline-treated mice, the significant increase in the reaction time to thermal pain was not detectable in both sodium salicylate and purified anthocyanin of Osbeckia species with the exception of morphine sulfate. However, the observation in morphine sulfate-treated animals was only noted at 45 and $60 \mathrm{~min}$. The reaction time was significantly different between the purified anthocyanin and morphine sulfate, i.e., commendable for morphine sulfate at 30,45 , and 60 min after treatment. No significant difference was observed between the purified anthocyanin and sodium salicylate.

\section{Writhing method}

Regarding the results of purified anthocyanin of Osbeckia sps. in the acetic acid-induced writhing test, a highly significant reduction in the writhes count was recorded as compared to control group (Table 7). Diclofenac showed the highest protection against the acetic acid-induced writhing (86.68\%), while silymarin (standard) showed $78.2 \%$ reduction in the writhes count. Purified anthocyanin of $O$. aspera revealed optimal protection at the given doses 150 and $200 \mathrm{mg} / \mathrm{kg}(64.7 \%$ and $82.4 \%$, respectively). No significant differences were noticed between purified anthocyanin and silymarin in the reduction of writhes count.

Purified anthocyanin of Osbeckia exhibited an excellent analgesic effect as compared to other concentrations at a dose of $200 \mathrm{mg} / \mathrm{kg}$. The 0 . aspera anthocyanin extracts showed maximum analgesic effect at all doses of $50,100,150$, and $200 \mathrm{mg} / \mathrm{kg}$ as compared to O. reticulata, control, and standard.

The purified anthocyanin of Osbeckia species was analyzed for analgesic activity by four different methods (tail immersion, analgesy meter, hot plate, and writhing methods). While anti-inflammatory activity was determined by carrageenan-induced paw edema. Both activities were determined at varying concentrations of $50,100,150$, and $200 \mathrm{mg} / \mathrm{kg}$. Silymarin and other respective drugs were used as standard reference.

Analgesic drugs act on central or peripheral nervous system to relieve pain selectively without affecting consciousness. Centrally functioning analgesics elevate the threshold for pain and also alter the physiological pain response. Meanwhile, peripherally acting drugs inhibit the generation of impulses at chemoreceptor region of pain. Tail-flick and hot plate methods were useful in justifying centrally mediated antinociceptive responses which target on changes above the spinal cord level or mediate a spinal reflex to a nociceptive stimulus. Hot plate method involves higher brain functions and was regarded a supraspinally organized response.

Tail immersion method which was used for evaluating centrally acting analgesic effects of drugs. In the present study, anthocyanin did not show any increase in latency. Analgesic effect against light stimuli may be elicited through opioid receptors or through modulation of several neurotransmitters [13]. The overall analgesic effect of purified anthocyanin of Osbeckia by thermal parameter was increased with passage of time, and the remarkable effect was achieved after 60 and $120 \mathrm{~min}$. Purified anthocyanin of Osbeckia exhibited significant analgesic effect than silymarin. Similarly, the pressure method is most sensitive to evaluate centrally acting analgesics [14]. Pain induced by the analgesy meter provides a model for the study of non-inflammatory pain. The analgesic effect of purified anthocyanin of Osbeckia was investigated by using analgesy meter method. The oral administration of purified anthocyanin of Osbeckia test involved the increased nociceptive threshold in mice, and it had increased up to $60 \mathrm{~min}$ and then reduced with passage of time. Significant reduction in the animal sensitivity to pain induced by pressure suggests the central protecting effect of purified anthocyanin of Osbeckia and was comparable to salicylic acid. The analgesic effect of purified anthocyanin of Osbeckia species was investigated using Eddy's hot plate method. This test analyzes the marked central analgesic effect as evidenced by a significant increase in reaction time. $O$. aspera and 0 . reticulata possess analgesic efficacy at all doses. Purified anthocyanin of 0 . aspera showed maximum activity at a dose of $200 \mathrm{mg} / \mathrm{kg}$ after $120 \mathrm{~min}$ by an increase in the reaction time (increase threshold potential of pain), and this may be due to the effective inhibition of prostaglandins synthesis. Writhing test is a chemical method used to induce pain of peripheral origin by injection of irritant principles such as phenylquinone or acetic acid in mice. Analgesic activity of the test compound is inferred from the decreased frequency of writhes. The manifestations of abdominal writhes in mice were described by Tasleem et al. (2014), an arching of back, extension of hind limbs, and contraction of abdominal musculature [12]. The writhing response is considered as a reflexive test. Signals transmitted to the central nervous system in response to pain due to irritation cause the release of mediators such as prostaglandins which contributes to the increased sensitivity to nociceptors. Purified anthocyanin of Osbeckia decreased the number of writhes significantly at all doses compared to reference drug diclofenac sodium (nonsteroidal anti-inflammatory drug) and control. Decreases in writhes were generally considered as an important parameter of analgesic activity in acetic acid-induced writhing test. Carrageenan-induced paw edema method was most widely used method for testing of nonsteroidal anti-inflammatory agents. Anti-inflammatory agents initially inhibit the cyclooxygenase enzyme which is involved in prostaglandin synthesis. Interestingly, the observed results of inhibition of edema volume by purified anthocyanin of Osbeckia at all doses with passage of time reveal its efficacy. These 
results indicate that anthocyanin possesses inhibition of prostaglandinmediated anti-inflammatory properties. Many phytochemicals were documented as anti-inflammatory drugs. For example, tannin of Quercus infectoria, phytochemicals from Scoparia dulcis, and tannin and flavonoid of Cassia auriculata and Boswellia dalzielii were proven anti-inflammatory plants [15-18]. Limonoids of Meliaceae was found to impart anti-inflammatory properties. Examples are the extracts of Khaya senegalensis, Triplochiton scleroxylon, and Azadirachta indica [19]. The anti-inflammatory effect of Opuntia ficus-indica was thought to be associated with the reduction of malondialdehyde level and increased activities of catalase, superoxide dismutase, and reduced glutathione [20]. Alkaloids including isoquinoline alkaloids, indole alkaloids, piperidine alkaloids, and quinazoline alkaloids obtained from plants also have anti-inflammatory properties [21]. Patwari et al., 2014, demonstrated the analgesic effect of Murdannia nudiflora [22]. Recently, Valenza et al. (2018) demonstrated the potential use of anthocyanins in the diet to control chronic inflammation [23]. Duarte et al. (2018) analyzed the anti-inflammatory mechanism of pelargonidin-3-Oglucoside and suggested that it involves the arrest of IkB- $\alpha$ activation and reduction in JNK ${ }^{\mathrm{MAPK}}$ phosphorylation [24].

\section{CONCLUSION}

A simple protocol for extraction and purification of anthocyanin from Osbeckia species was established. Fractionation revealed a pool of anthocyanins such as malvidin-3-diglucoside, delphinidin, cyanidin aglycone, and peonidin. Further, the results suggest that purified anthocyanin of Osbeckia possesses significant analgesic and anti-inflammatory activities. Interestingly, anthocyanin of 0 . aspera revealed sound analgesic and anti-inflammatory activities than 0 . reticulata. Acute toxicity assessment results indicated no mortality at a dose of $3000 \mathrm{mg} / \mathrm{kg}$. The analgesic activity of anthocyanin with the characteristic profile of slow onset and prolonged duration reveals that anthocyanin of Osbeckia species was a potential source for future medicine.

\section{ACKNOWLEDGMENTS}

This work was supported by the University Grant Commission (UGC), Bengaluru, in connection with the FDP and also by Kerala State Council for Science, Technology, and Environment (KSCSTE), Government of Kerala.

\section{CONFLICTS OF INTEREST}

The authors hereby declare that we have no conflicts of interest.

\section{REFERENCES}

1. Lawarence B, Murugan K. Folklore use of Osbeckia species from Munnar hills, Kerala. J Tradit Folk Pract 2017;5:131-41.

2. Jayaweera DM. Medicinal Plants (Indigenous and Exotic) Used in Ceylon. Part I. Colombo: National Science Council of Sri Lanka; 1981. p. 205-6.

3. Aswathy JM, Sumayya SS, Lawarence B, Kavitha CH, Murugan K. Purification, fractionation and characterization of anthocyanin from in vitro culture of Bridelia retusa (L) spreng. Indian J Pharm Sci 2018;80:52-64.

4. Huang W, Yan Z, Li D, Ma Y, Zhou J, Sui Z. Antioxidant and antiinflammatory effects of blueberry anthocyanins on high glucose- induced human retinal capillary endothelial Cells. Oxid Med Cell Longev 2018;2018:1-10.

5. Bishayee A, Háznagy-Radnai E, Mbimba T, Sipos P, Morazzoni P, Darvesh AS, et al. Anthocyanin-rich black currant extract suppresses the growth of human hepatocellular carcinoma cells. Nat Prod Commun 2010;5:1613-8.

6. Murashige T, Skoog F. A revised medium for rapid growth and bio assays with tobacco tissue cultures. Physiol Plant 1962;15:473-97.

7. Sutharut J, Sudarat J. Total anthocyanin content and antioxidant activity of germinated colored rice. Int Food Res J 2012;19:215-21.

8. OECD. Acute Oral Toxicity-Fixed Dose Procedure (chptr). OECD Guideline Test Chemicals; 2001. p. 1-14.

9. OECD. OECD Guideline for the Testing of Chemicals: Repeated Dose 90-Day Oral Toxicity Study In Rodents; 1998.

10. Meshram GG, Kumar A, Rizvi W, Tripathi CD, Khan RA. Evaluation of the anti-inflammatory activity of the aqueous and ethanolic extracts of the leaves of Albizia lebbeck in rats. J Tradit Complement Med 2016;6:172-5

11. Vogel HG. Drug Discovery and Evaluation : Pharmacological Assays. Berlin: Springer; 2008

12. Tasleem F, Azhar I, Ali SN, Perveen S, Mahmood ZA. Analgesic and anti-inflammatory activities of Piper nigrum L. Asian Pac J Trop Med 2014;7S1:S461-8

13. Liang X, Liu R, Chen C, Ji F, Li T. Opioid system modulates the immune function: A review. Transl Perioper Pain Med 2016;1:5-13.

14. Tamrat Y, Nedi T, Assefa S, Teklehaymanot T, Shibeshi W. Antiinflammatory and analgesic activities of solvent fractions of the leaves of Moringa stenopetala bak. (Moringaceae) in mice models. BMC Complement Altern Med 2017;17:473.

15. Fan SH, Ali NA, Basri DF. Evaluation of analgesic activity of the methanol extract from the galls of Quercus infectoria (Olivier) in rats. Evid Based Complement Alternat Med 2014;2014:976764.

16. Moniruzzaman M, Rahman MA, Ferdous A. Evaluation of sedative and hypnotic activity of ethanolic extract of Scoparia dulcis Linn. Evid Based Complement Alternat Med 2015;2015:873954.

17. Kuete V, Karaosmanoğlu O, Sivas H. Anticancer activities of african medicinal spices and vegetables. Medicinal Spices and Vegetables from Africa. London: Elsevier; 2017. p. 271-97.

18. Adebisi MI, Abubakar A, Abubakar K, Giaze RT. Analgesic effect and anti-inflammatory activity of aqueous extract of Boswellia dalzielii (burseraceae) stem bark. Int J Pharm Pharm Sci 2018;10:139-42.

19. Agyare C, Spiegler V, Asase A, Scholz M, Hempel G, Hensel A. An ethnopharmacological survey of medicinal plants traditionally used for cancer treatment in the Ashanti Region, Ghana. J Ethnopharmacol 2018;212:137-52.

20. Ammar I, Salem MB, Harrabi B, Mzid M, Bardaa S, Sahnoun Z, et al. Anti-inflammatory activity and phenolic composition of prickly pear (Opuntia ficus-indica) flowers. Ind Crops Prod 2018;112:313-9.

21. Hashmi MA, Khan A, Farooq U, Khan S. Alkaloids as cyclooxygenase inhibitors in anticancer drug discovery. Curr Protein Pept Sci 2018;19:292-301.

22. Patwari BN, Ahmed AB, Das T, Sengupta R. Phytochemical screening and analgesic effects of ethanolic extract of plant Murdania nudiflora (L) Brenan (Commelinaceae) in albino mice using hot plate method. Int J Pharm Pharm Sci 2014;6:512-5.

23. Valenza A, Bonfanti C, Pasini ME, Bellosta P. Anthocyanins function as anti-inflammatory agents in a drosophila model for adipose tissue macrophage infiltration. Biomed Res Int 2018;2018:1-9.

24. Duarte LJ, Chaves VC, Nascimento MV, Calvete E, Li M, Ciraolo E, et al. Molecular mechanism of action of pelargonidin-3-O-glucoside, the main anthocyanin responsible for the anti-inflammatory effect of strawberry fruits. Food Chem 2018;247:56-65. 